\title{
The prognostic value of IL10 and TNF alpha functional polymorphisms in premenopausal early-stage breast cancer patients
}

Erika Korobeinikova ${ }^{*}$, Dana Myrzaliyeva ${ }^{1}$, Rasa Ugenskiene², Danguole Raulinaityte², Jurgita Gedminaite ${ }^{1}$ Kastytis Smigelskas ${ }^{3}$ and Elona Juozaityte ${ }^{1}$

\begin{abstract}
Background: Interleukin-10 and tumor necrosis factor a play an important role in breast carcinogenesis. Genes, encoding those two cytokines, contain single nucleotide polymorphisms, which are associated with differential levels of gene transcription. This study analyzes single nucleotide polymorphisms in interleukin 10 and tumor necrosis factor a genes and their contribution to breast cancer phenotype, lymph node status and survival in a group of young Lithuanian women with early-stage breast cancer patients.
\end{abstract}

Results: We genotyped 100 premenopausal Eastern European (Lithuanian) patients with stage I-II breast cancer, $\leq 50$ years old at the time of diagnosis, for interleukin $10-592 \mathrm{~A}>\mathrm{C},-819 \mathrm{C}>\mathrm{T}$ and $-1082 \mathrm{~A}>\mathrm{G}$ and tumor necrosis factor $a-308 \mathrm{G}>\mathrm{A}$ single nucleotide polymorphisms in the gene promoter region. We used the polymerase chain reaction, namely a restriction fragment length polymorphism method, for a SNP analysis. All genotypes were in Hardy-Weinberg equilibrium and had the same distribution as the HapMap CEU population. Holders of IL $10-592 \mathrm{~A}>\mathrm{C}$ heterozygous IL10 -592 AC genotype had a higher probability of estrogen receptor positive breast cancer phenotype than homozygous variants $(P=0.017)$. Phased ACC haplotype of IL10 polymorphisms was associated with younger age of diagnosis $(P=0.017)$. Of all the tested single nucleotide polymorphisms, only $T N F a-308 G>A$ has revealed a prognostic capability for breast cancer survival. GA genotype carriers, compared to GG, showed a significant disadvantage in progression-free survival $(P=0.005$, adjusted hazard ratio $(H R)=4.631,95 \%$ confidence interval $(C l)=1.587-13.512)$, metastasis-free survival $(P=0.010, H R=4.708,95 \% \mathrm{Cl}=1.445-15.345)$ and overall survival $(\mathrm{P}=0.037, \mathrm{HR}=4.829,95 \% \mathrm{Cl}=1.098-21.243)$.

Conclusions: According to our data, IL10-1082A > G, -819 T > C, -592A > C polymorphisms and phased haplotypes have not revealed a prognostic value for breast cancer. On the contrary, the TNFa -308 polymorphism might modulate the risk and contribute to the identification of patients at a higher risk of breast cancer recurrence, metastasis and worse overall survival among young Lithuanian early-stage breast cancer patients.

Keywords: Breast cancer, Prognosis, IL10, TNFalpha, Single nucleotide polymorphism, SNP

\footnotetext{
* Correspondence: erikakorobeinikova@gmail.com

${ }^{1}$ Oncology Institute, Lithuanian University of Health Sciences, Eiveniu str. 2, LT-50009 Kaunas, Lithuania

Full list of author information is available at the end of the article
} 


\section{Background}

Breast cancer $(\mathrm{BC})$ comprises about one fourth of all female cancers worldwide. Despite new diagnostic and treatment options, roughly $30 \%$ of early-stage patients will progress to metastatic disease [1]. Experimental genetic research and genome-wide association studies have significantly improved our understanding of complex $\mathrm{BC}$ biology, the process of the disease development in particular. However, it is equally important to extend our knowledge on the course the disease takes by following its development to identify patients who are likely to have a more aggressive disease and to tailor their treatment.

It has been well established that several cytokines, including Interleukin-10 (IL-10) and Tumor Necrosis Factor $\alpha(\mathrm{TNF} \alpha)$, have a crucial role in a coordinated manner in breast carcinogenesis [2]. Genes, encoding IL-10 and TNF $\alpha$ cytokines, contain several nucleotide variations, namely single nucleotide polymorphisms (SNPs), which are associated with different levels of gene transcription and determine interindividual differences in IL-10 and TNF $\alpha$ production $[3,4]$.

Over the recent years, three functional SNPs, constituting substitutions of a single bases upstream of the transcriptional start site of IL10 gene, have been investigated: IL10 adenine (A) to guanin (G) substitution at -1082 bp (rs1800896), IL10 thymin (T) to cytosine (C) substitution at $-819 \mathrm{bp}$ (rs1800871) and IL10 A to C substitution at -592 bp (rs1800872) [5]. These SNPs affect transcriptional activity, leading to alterations in gene expression that influence IL-10 production [3, 4]. They are strongly linked together and present three major haplotypes, ATA, ACC, and GCC, which are associated with low, medium and high levels of IL10 expression respectively. GCC individuals secrete on average two or three times more IL-10 than wild type ATA individuals [6]. It was proven by several authors that IL-10 levels in blood samples of breast cancer patients correlate directly with the clinical stage of the disease $[7,8]$.

SNP in the promoter region of the TNF $\alpha$ locus has been identified at position -308 , which also showed that it involves the replacement of $\mathrm{G}$ by A [9]. TNF $\alpha-308 \mathrm{G}>\mathrm{A}$ GA and AA genotypes lead to a higher rate of TNF $\alpha$ gene transcription than wild type GG genotype in vitro [10]. High plasma TNF $\alpha$ levels in cancer patients are associated with a poor disease outcome [11]. TNF $\alpha$ expression significantly increases at the advanced stages of breast cancer [12]. The TNF $\alpha$ protein induces the expression of adhesion molecules, facilitating the invasion of metastatic tumor cells [13]. Several studies have shown a close link between TNF $-308 \mathrm{G}>\mathrm{A}$ polymorphism and breast cancer risk [14].

Some investigators found genetic evidence for association between IL10 -1082A > G, $-819 \mathrm{~T}>\mathrm{C},-592 \mathrm{~A}>\mathrm{C}$ and TNF $\alpha-308 \mathrm{G}>\mathrm{A}$ polymorphisms and breast cancer progression in different ethnic populations $[8,15]$. However, the data is not consistent [5], poorly differentiated in terms of ethnicity, cancer stage, age etc. This study, therefore, aimed to investigate the relationship between functional SNPs in ILIO and TNF $\alpha$ and BC clinicopathologic features and survival in a highly homogeneous group of patients, taking into account age, race and stage of the disease at the time of diagnosis to identify whether these genetic determinants may be important for $\mathrm{BC}$ prognosis.

\section{Materials and Methods Patients}

Adult female primary stage I-II BC patients $(\leq 50$ years old at the time of diagnosis) in premenopausal state $(n=100)$ were involved in this research. Women with other malignant tumors, poor performance status, other significant comorbidities and/or incomplete medical documentation were not included in the study. Adjuvant therapy was chosen by clinicians, based on pathomorphological characteristics and validated prognosis factors, according to national recommendations. All the study subjects were Eastern European (Lithuanian).

\section{Specimen Characteristics and Assay Methods}

Samples were collected in 2009-2014. Genomic DNA was extracted from peripheral blood leukocytes by using the commercially available DNA extraction kit (Thermo Fisher Scientific), with regard to the manufacturer's protocol. A IL10 gene promoter polymorphisms analysis was performed by using a polymerase chain reactionbased restriction fragment length polymorphism method (PCR-RFLP).

IL10 gene regions including $-592 \mathrm{~A}>\mathrm{C},-819 \mathrm{C}>\mathrm{T}$ and $-1082 \mathrm{~A}>\mathrm{G}$ polymorphic sites were amplified by using primers reported by Liu et al. [16]. For $-592 \mathrm{C}>\mathrm{A}$ and $-819 \mathrm{C}>\mathrm{T}$ polymorphisms, the same reaction mixture composition was employed. Briefly, PCR reaction was carried out in a total volume of $25 \mu \mathrm{l}$, containing 1x DreamTaq standard buffer, template DNA, 0.24 $\mu \mathrm{M}$ of each primer, $200 \mu \mathrm{M}$ of each dNTP and $1.25 \mathrm{U}$ of DreamTaq DNA polymerase (Thermo Fisher Scientific, Waltham, MA, USA) with annealing at $63{ }^{\circ} \mathrm{C}$ and $58{ }^{\circ} \mathrm{C}$ for $-592 \mathrm{C}>\mathrm{A}$ and $-819 \mathrm{C}>\mathrm{T}$ polymorphisms respectively. PCR reaction conditions for $I l 10$ gene $-1082 \mathrm{G}>\mathrm{A}$ polymorphism were slightly modified by adding $4.0 \mathrm{mM} \mathrm{MgCl}_{2}, 4 \% \mathrm{DMSO}$ and changing the annealing temperature to $56^{\circ} \mathrm{C}$.

Following PCR, the amplicons underwent digestion with different restriction endonucleases. RsaI restriction endonuclease (Thermo Fisher Scientific Baltics, Lithuania) was used for a $-592 \mathrm{C}>\mathrm{A}$ polymorphism analysis. In the presence of A allele, RsaI yielded 175 and 237 bp fragments, while $\mathrm{C}$ allele remained uncut (412 bp). MaeIII restriction 
endonuclease was implemented for a $-819 \mathrm{C}>\mathrm{T}$ polymorphism detection. The presence of MaeIII restriction site indicated $\mathrm{C}$ allele (125 and 84 bp fragments), while $\mathrm{T}$ allele remained undigested (209 bp). For a $-1082 \mathrm{G}>\mathrm{A}$ polymorphism identification, PCR products were incubated with MnlI enzyme (Thermo Fisher Scientific Baltics, Lithuania), which cut $\mathrm{G}$ allele into 106 and 33 bp fragments, while A allele remained uncut (139 bp). The results were visualized on $2 \%$ agarose gel containing ethidium bromide.

The primer sequences for a TNF $\alpha-308 \mathrm{G}>\mathrm{A}$ fragment amplification were reported by Kaur et al. [17]. PCR reaction was carried out in a total volume of $25 \mu \mathrm{l}$, containing 1x DreamTaq standard buffer, template DNA, $0.24 \mu \mathrm{M}$ of each primer, $200 \mu \mathrm{M}$ of each dNTP, $4.0 \mathrm{mM} \mathrm{MgCl}_{2}, 4 \%$ DMSO and $1.25 \mathrm{U}$ of DreamTaq DNA polymerase (Thermo Fisher Scientific, Waltham, MA, USA). The annealing temperature for $T N F \alpha-308 \mathrm{G}>\mathrm{A}$ polymorphism was $63^{\circ} \mathrm{C}$.

Restriction endonuclease $\mathrm{NcoI}$ was used to detect the $T N F \alpha-308 \mathrm{G}>\mathrm{A}$ polymorphism. With regard to TNFa $-308 \mathrm{G}>\mathrm{A}$ promoter polymorphism, $\mathrm{G}$ allele was represented by $87 \mathrm{bp}$ and $20 \mathrm{bp}$ fragments, while A allele by 107 bp fragment. Restriction endonuclease products were separated on $3 \%$ agarose gels containing ethiduim bromide.

\section{Study Design}

A prospective cohort study was conducted at the Oncology Institute of Lithuanian University of Health Sciences. A full ethical approval was obtained from the Kaunas Regional Bioethics Committee (protocol number BE-2-13) and the Lithuanian Data Protection Agency (protocol number 2R-2246). Every subject has signed informed consent forms before commencing the study. For a case selection, the information of the period of 2001-2011 about primarily $\mathrm{BC}$ patients was retrieved from the Pathology Department at the Hospital of Lithuanian University of Health Sciences. The patients were matched by disease stage, age of disease onset and menopausal status. The patients' clinicopathological information was obtained from their medical files. The patients were monitored according to the clinical monitoring protocol till $1^{\text {st }}$ May 2014. The median follow-up was 70 months. Disease progression was defined as a local breast cancer recurrence in the affected breast and distant metastases in visceral organs, skeleton, skin or the central nervous system. Date of cancer histological verification was considered as time zero for survival analysis. The SNPs selected for associations with the known breast cancer prognostic factors and cancer progression were as follows: IL10 $-1082 \mathrm{~A}>\mathrm{G}$, $-819 \mathrm{~T}>\mathrm{C},-592 \mathrm{~A}>\mathrm{C}$, and TNF $\alpha-308 \mathrm{G}>\mathrm{A}$. This study was conducted adhering to recommendations for tumor marker prognostic studies $[18,19]$.

\section{Statistical Analysis}

A Hardy-Weinberg Equilibrium for the genotype distribution of the selected SNPs was tested in all cases by using the Pearson $\mathrm{X}^{2}$ test and the Fisher Exact test. To evaluate if the frequencies of alleles and genotypes correspond with the data of earlier studies, we retrieved information from a population of the International HapMap project of Northern Europeans from Utah (CEU) (HapMap Data rel 28 Phasell + III, August10, on NCBI B36 assembly, dbSNP b126, http://hapmap.ncbi.nlm.nih.gov). IL10 haplotypes were inferred from promoter IL10 SNPs by Bayesian methods as implemented in the Phase software (version 2.1; Department of Statistics, University of Washington, Seattle, Washington, USA) [20, 21]. For demonstration of linkage disquelibrium (LD) SNP block was performed using Haploview v4.1. The block followed the haplotype block definition of solid spine of LD as implemented in Haploview v4.1 [22]. Statistical analyses were performed by using SPSS ${ }^{\odot}$ for Windows software version 20.0 (Released 2011. Armonk, NY: IBM Corp.). P value of less than 0.05

Table 1 Frequencies of clinical and tumor biological factors

\begin{tabular}{ll}
\hline Age group & \\
\hline $30-40 y e a r s$ & $34 / 100$ \\
$41-50$ years & $66 / 100$ \\
Tumor size (pathologic) & \\
T1 & $64 / 100$ \\
T2 & $36 / 100$ \\
Lymph node involvement (pathologic) & \\
No & $55 / 100$ \\
N1 & $45 / 100$ \\
Grade & \\
G1 & $9 / 100$ \\
G2 & $62 / 100$ \\
G3 & $29 / 100$ \\
Estrogen receptors (ER) & \\
ER positive & $57 / 100$ \\
ER negative & $43 / 100$ \\
Progestin receptors (PR) & \\
PR positive & $48 / 100$ \\
PR negative & $52 / 100$ \\
Human epidermal growth factor receptor 2 (HER2) & \\
HER2 positive & $28 / 100$ \\
HER2 negative & $72 / 100$ \\
Intrinsic subtype & \\
Luminal A & $46 / 100$ \\
Luminal B & $18 / 100$ \\
HER2 enriched & $10 / 100$ \\
'Basal-like' & $26 / 100$ \\
\hline & \\
\hline
\end{tabular}


was considered significant. Bonferroni-corrected alpha level was used in association analysis for multiple comparisons. The Pearson Chi-square or the Fisher Exact test was used for categorical data. Associations between genotype and disease-free survival (DFS), metastasis-free survival (MFS) and overall survival (OS) were investigated by using Kaplan-Meier's method and estimated by performing a log-rank test. The association analysis included genotype, allelic models and haplotype model for IL10 SNPs. Cox regression models were used to adjust the analysis for potential confounders. SNPs were re-evaluated in a model adjusted for the known breast cancer prognostic values, which included age group (30-40 years, 41-50 years), tumor size (T1, 2), lymph node status (N0, 1), histological grade (G1, 2, 3) and intrinsic subtype (Luminal A, Luminal B, HER2 enriched, Basal-like), by carrying out a multivariate regression analysis as well as computing odds ratios and $95 \%$ confidence intervals (95\% CI).

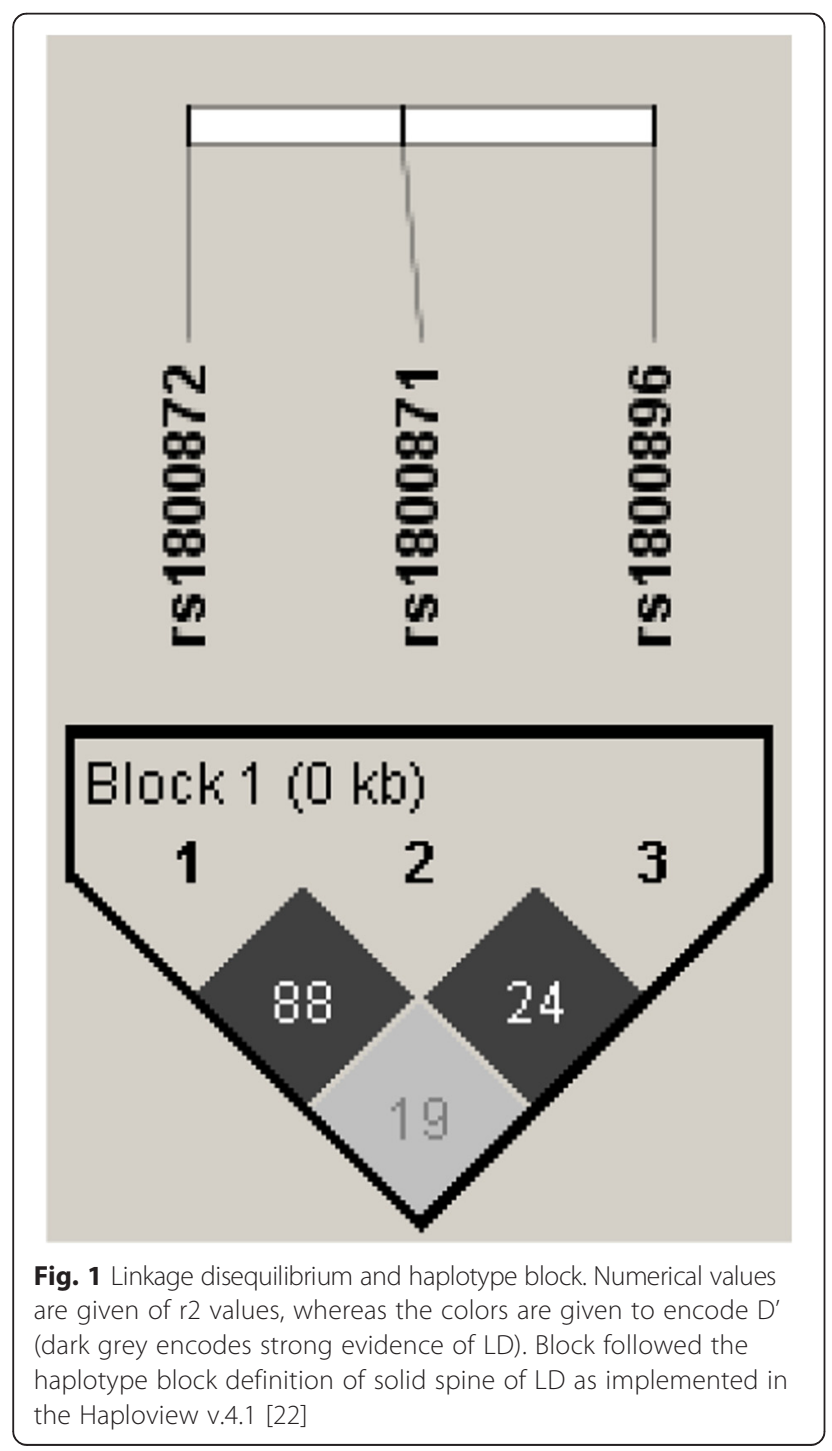

Table 2 Allele and genotype frequencies of the $I L 10$ and TNFa gene promoter regions. Data from our study and HapMap CEU population

\begin{tabular}{|c|c|c|c|c|c|c|}
\hline \multirow{3}{*}{$\begin{array}{l}\text { Gene } \\
T N F a\end{array}$} & \multirow{3}{*}{$\begin{array}{l}\text { Polymorphism } \\
\begin{array}{l}\text {-308 G > A } \\
\text { (rs1800629) }\end{array}\end{array}$} & \multirow{2}{*}{\multicolumn{5}{|c|}{$\begin{array}{l}\text { Allele and genotype frequencies } \\
\text { (HAPMAP CEU allele and genotype } \\
\text { frequencies data) }\end{array}$}} \\
\hline & & & & & & \\
\hline & & G & A & \multirow[t]{2}{*}{ GG } & GA & $A A$ \\
\hline & & 0.900 & 0.100 & & 0.14 & 0.03 \\
\hline & & $(0.827)$ & $(0.173)$ & $(0.877)$ & $(0.123)$ & (0) \\
\hline \multirow[t]{9}{*}{$1 L 10$} & $-1082 A>G$ & A & G & AA & GA & GG \\
\hline & & 0.415 & 0.585 & 0.20 & 0.43 & 0.37 \\
\hline & & $(0.469)$ & $(0.531)$ & $(0.212)$ & $(0.513)$ & $(0.274)$ \\
\hline & $-819 \mathrm{~T}>\mathrm{C}$ & $\mathrm{T}$ & C & CC & $C T$ & $\pi$ \\
\hline & & 0.255 & 0.745 & 0.58 & 0.33 & 0.09 \\
\hline & & $(0.179)$ & $(0.821)$ & $(0.661)$ & $(0.321)$ & $(0.018)$ \\
\hline & $-592 \mathrm{~A}>\mathrm{C}(\mathrm{rs} 1800872)$ & C & A & CC & $A C$ & AA \\
\hline & & 0.720 & 0.280 & 0.54 & 0.36 & 0.10 \\
\hline & & $(0.788)$ & $(0.212)$ & (0.628) & (0.319) & $(0.053)$ \\
\hline
\end{tabular}

\section{Results}

\section{Sample Characteristics}

The analysis included 100 primary, young, premenopausal, early stage breast cancer patients. The frequency data for clinical and tumor biological factors is shown in Table 1. All the patients were genotyped for a panel of four SNPs: IL10 $-1082 \mathrm{~A}>\mathrm{G},-819 \mathrm{~T}>\mathrm{C},-592 \mathrm{~A}>\mathrm{C}$, and $T N F \alpha-308 \mathrm{G}>\mathrm{A}$. The genotypes were found to be in Hardy-Weinberg equilibrium in all the four SNPs. A strong LD was confirmed for IL10 -819 T allele with IL10 -592A allele and IL10 -819 C allele with IL10 $-592 \mathrm{C}$ allele (Fig. 1). Our cohort statistically has the same genotype distribution as the HapMap CEU population. The allele and genotype frequencies determined in our study and, for comparison, HapMap CEU population are shown in Table 2.

\section{Inferential Analysis}

The estimation of associations between the known $\mathrm{BC}$ prognostic variables and the studied polymorphisms in genotype model revealed a significant link between IL10 $-592 \mathrm{~A}>\mathrm{C}$ SNP and ER status $(\mathrm{P}=0.017)$. The

Table 3 Relative haplotype frequencies of IL10 promoter polymorphism on the total number of chromosomes

\begin{tabular}{ll}
\hline Haplotype & Frequencies (valid percent ${ }^{*}$ ) \\
\hline GCC & $41 \%$ \\
ACC & $32.8 \%$ \\
ATA & $26.2 \%$
\end{tabular}

*2 rare ACA and 3 GCA haplotypes were not included in the haplotype association analysis 
Table 4 Cox's univariate model. Unajusted hazard ratios for PFS, MFS, OS with each of the SNPs in genotype, allelic and haplotype model

\begin{tabular}{|c|c|c|c|c|c|c|c|c|c|}
\hline \multirow{2}{*}{\multicolumn{2}{|c|}{ Reference SNP ID }} & \multirow{3}{*}{$\begin{array}{l}\text { Genotype/allele } \\
\text { /haplotype }\end{array}$} & \multirow[t]{3}{*}{$n$} & \multirow{2}{*}{\multicolumn{2}{|c|}{ Progression-free survival }} & \multicolumn{2}{|c|}{$\underline{\text { Metastasis-free survival }}$} & \multicolumn{2}{|l|}{ Overall survival } \\
\hline & & & & & & & & & \\
\hline & & & & $\begin{array}{l}\text { Multivariate } \\
\text { Hazard ratio }(\mathrm{Cl})\end{array}$ & $\begin{array}{l}P \\
\text { value }\end{array}$ & $\begin{array}{l}\text { Multivariate } \\
\text { Hazard ratio (Cl) }\end{array}$ & $\begin{array}{l}P \\
\text { value }\end{array}$ & $\begin{array}{l}\text { Multivariate } \\
\text { Hazard ratio }(\mathrm{Cl})\end{array}$ & $\begin{array}{l}P \\
\text { value }\end{array}$ \\
\hline \multirow[t]{11}{*}{ IL10 -1082A > G } & \multirow{5}{*}{$\begin{array}{l}\text { Genotype } \\
\text { model }\end{array}$} & GG & 37 & 1 & 0.317 & 1 & 0.456 & 1 & 0.288 \\
\hline & & GA & 43 & 3.168 & 0.131 & 2.580 & 0.221 & 1.524 & 0.606 \\
\hline & & & & $(0.709-14.157)$ & & $(0.565-11.779)$ & & $(0.307-7.565)$ & \\
\hline & & AA & 20 & 2.840 & 0.182 & 2.493 & 0.248 & 3.138 & 0.168 \\
\hline & & & & $(0.613-13.169)$ & & $(0.592-11.753)$ & & $(0.617-15.951)$ & \\
\hline & \multirow{6}{*}{$\begin{array}{l}\text { Allelic } \\
\text { model }\end{array}$} & A allele non carriers & 63 & 1 & & 1 & & 1 & \\
\hline & & A allele carriers & 37 & 3.020 & 0.135 & 0.819 & 0.663 & 0.431 & 0.128 \\
\hline & & & & $(0.708-12.885)$ & & $(0.334-2.008)$ & & $(0.145-1.276)$ & \\
\hline & & $\mathrm{G}$ allele non carriers & 80 & 1 & & 1 & & 1 & \\
\hline & & G allele carriers & 20 & 0.852 & 0.708 & 2.541 & 0.211 & 2.021 & 0.359 \\
\hline & & & & $(0.367-1.974)$ & & $(0.589-10.953)$ & & $(0.450-9.086)$ & \\
\hline \multirow[t]{11}{*}{ IL $10-819 T>C$} & \multirow{5}{*}{$\begin{array}{l}\text { Genotype } \\
\text { model }\end{array}$} & $\mathrm{CC}$ & 58 & 1 & 0.695 & 1 & 0.905 & 1 & 0.357 \\
\hline & & $\mathrm{CT}$ & 33 & 1.456 & 0.396 & 1.234 & 0.665 & 2.029 & 0.242 \\
\hline & & & & $(0.612-3.466)$ & & $(0.477-3.188)$ & & $(0.620-6.643)$ & \\
\hline & & $\pi$ & 9 & 1.109 & 0.892 & 1.176 & 0.833 & 2.516 & 0.253 \\
\hline & & & & $(0.248-4.963)$ & & $(0.260-5.314)$ & & $(0.518-12.221)$ & \\
\hline & \multirow{6}{*}{$\begin{array}{l}\text { Allelic } \\
\text { model }\end{array}$} & C allele non carriers & 91 & 1 & & 1 & & 1 & \\
\hline & & C allele carriers & 9 & 1.042 & 0.956 & 0.918 & 0.909 & 0.502 & 0.370 \\
\hline & & & & $(0.244-4.447)$ & & $(0.213-3.960)$ & & $(0.111-2.265)$ & \\
\hline & & T allele non carriers & 42 & 1 & & 1 & & 1 & \\
\hline & & T allele carriers & 58 & 1.378 & 0.444 & 1.220 & 0.658 & 2.157 & 0.161 \\
\hline & & & & $(0.606-3.131)$ & & $(0.505-2.950)$ & & $(0.736-6.322)$ & \\
\hline \multirow[t]{11}{*}{ IL10 -592A >C } & \multirow{5}{*}{$\begin{array}{l}\text { Genotype } \\
\text { model }\end{array}$} & $\mathrm{CC}$ & 54 & 1 & 0.877 & 1 & 0.995 & 1 & 0.427 \\
\hline & & $A C$ & 36 & 1.131 & 0.637 & 1.048 & 0.923 & 1.849 & 0.311 \\
\hline & & & & $(0.517-2.935)$ & & $(0.405-2.709)$ & & $(0.563-6.073)$ & \\
\hline & & $\mathrm{AA}$ & 10 & 0.941 & 0.941 & 1.011 & 0.989 & 2.411 & 0.276 \\
\hline & & & & $(0.211-4.231)$ & & $(0.224-4.570)$ & & $(0.495-11.728)$ & \\
\hline & \multirow{6}{*}{$\begin{array}{l}\text { Allelic } \\
\text { model }\end{array}$} & $\mathrm{C}$ allele non carriers & 90 & 1 & & 1 & & 1 & \\
\hline & & C allele carriers & 10 & 1.152 & 0.848 & 1.007 & 0.992 & 0.512 & 0.384 \\
\hline & & & & $(0.270-4.920)$ & & $(0.233-4.347)$ & & $(0.114-2.311)$ & \\
\hline & & A allele non carriers & 46 & 1 & & 1 & & 1 & \\
\hline & & A allele carriers & 54 & 1.168 & 0.712 & 1.039 & 0.932 & 1.992 & 0.211 \\
\hline & & & & $(0.513-2.656)$ & & $(0.430-2.515)$ & & $(0.676-5.863)$ & \\
\hline \multirow[t]{8}{*}{ TNFa-308G > A } & Genotype & GG & 83 & 1 & 0.066 & 1 & 0.135 & 1 & 0.163 \\
\hline & & GA & 14 & $3.049^{*}$ & 0.020 & $2.819^{*}$ & 0.045 & 3.096 & 0.057 \\
\hline & & & & (1.195-7.778) & & $(1.021-7.780)$ & & $(0.967-9.909)$ & \\
\hline & & AA & 3 & N.c. & 0.981 & N.c. & 0.982 & N.c. & 0.989 \\
\hline & Allelic & $\mathrm{G}$ allele non carriers & 97 & 1 & & 1 & & 1 & \\
\hline & & $\mathrm{G}$ allele carriers & 3 & 21.241 & 0.548 & 21.252 & 0.992 & 21.069 & 0.725 \\
\hline & & & & $(0.001 ;>1000)$ & & $(0.001 ;>1000)$ & & $(0.001 ;>1000)$ & \\
\hline & & A allele non carriers & 17 & 1 & & 1 & & 1 & \\
\hline
\end{tabular}


Table 4 Cox's univariate model. Unajusted hazard ratios for PFS, MFS, OS with each of the SNPs in genotype, allelic and haplotype model (Continued)

\begin{tabular}{|c|c|c|c|c|c|c|c|c|c|}
\hline & & A allele carriers & 83 & 2.256 & 0.088 & 2.904 & 0.153 & 2.643 & 0.102 \\
\hline & & & & $(0.887-5.738)$ & & $(0.760-5.768)$ & & $(0.825-8.471)$ & \\
\hline \multirow[t]{9}{*}{ IL10 } & \multirow{9}{*}{$\begin{array}{l}\text { Haplotype } \\
\text { model }\end{array}$} & GCC non carriers & 43 & 1 & & 1 & & 1 & \\
\hline & & GCC carriers & 57 & 1.502 & 0.353 & 1.483 & 0.401 & 1.143 & 0.805 \\
\hline & & & & $(0.637-3.544)$ & & $(0.592-3.718)$ & & $(0.396-3.300)$ & \\
\hline & & ACC non carriers & 38 & 1 & & 1 & & 1 & \\
\hline & & ACC carriers & 62 & 0.890 & 0,785 & 0.854 & 0.730 & 0.456 & 0.154 \\
\hline & & & & $(0.384-2.063)$ & & $(0.348-2.095)$ & & $(0.155-1.343)$ & \\
\hline & & ATA non carriers & 58 & 1 & & 1 & & 1 & \\
\hline & & ATA carriers & 42 & 1.374 & 0.448 & 1.214 & 0.667 & 2.104 & 0.174 \\
\hline & & & & $(0.605-3.121)$ & & $(0.502-2.935)$ & & $(0.720-6.150)$ & \\
\hline
\end{tabular}

*Significant associations.

N.c. - no cases

carriers of heterozygous AC genotype had 3.231 times higher probability of ER positive BC phenotype than CC genotype carriers (95 \% CI $1.282-8.141$; P = 0.011) and 4.500 times higher than AA genotype carriers (95 \% CI 1.032 - 19.630; P =0.037). The allelic model showed no close relationships of IL10 -592A > C SNP with tumor biological and clinical prognostic factors.
The analysis of $I L 10-1082 \mathrm{~A}>\mathrm{G}, I L 10-819 \mathrm{~T}>\mathrm{C}$ and TNF $\alpha-308 \mathrm{G}>\mathrm{A}$ SNPs in both genotype and allelic models showed no significant links with clinicopathological features.

Phasing revealed three main, well-known haplotypes, namely GCC, ACC and ATA. A few uncommon haplotypes were confirmed (ACA and GCA), which were not included

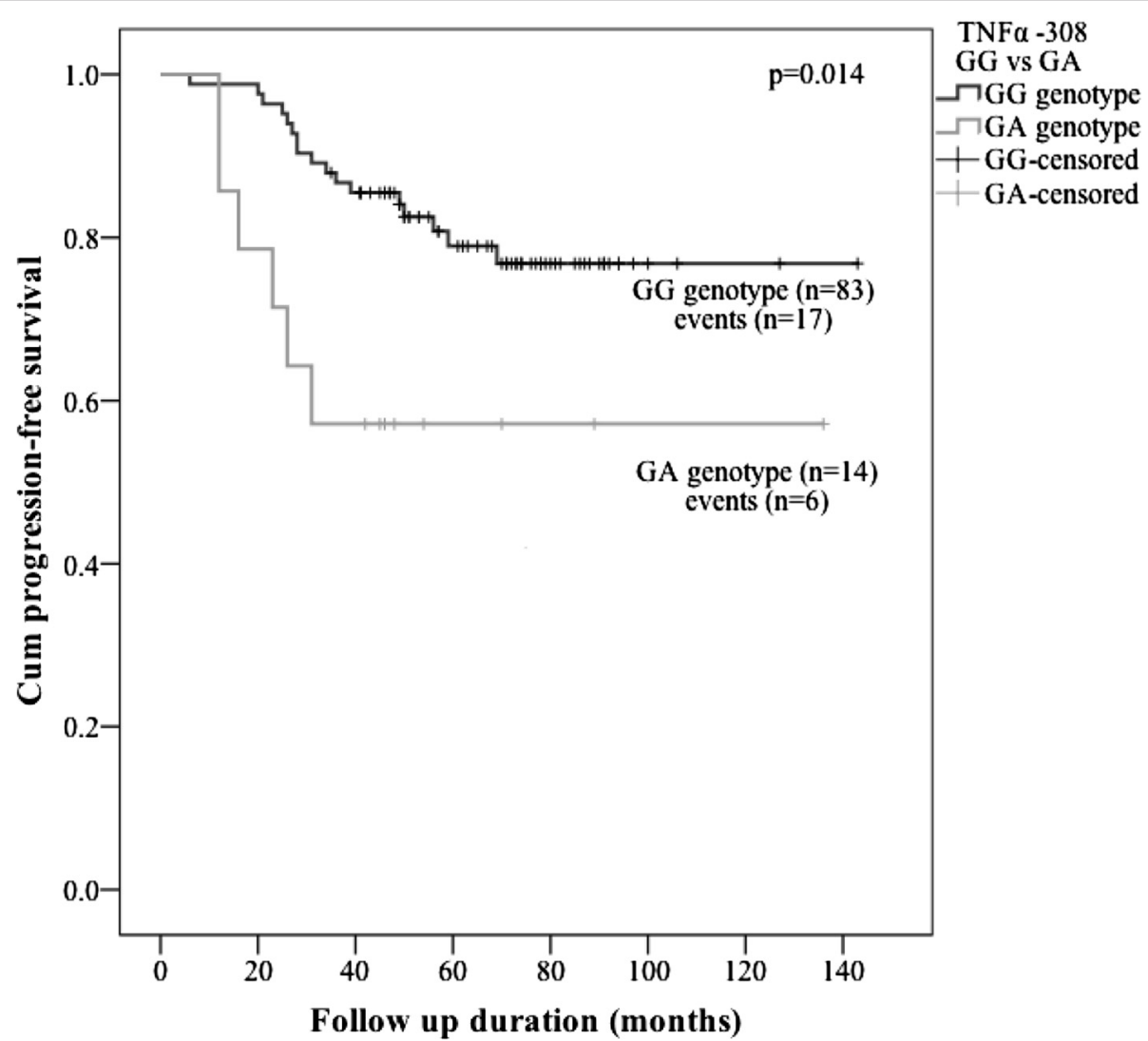

Fig. 2 Kaplan-Meier curves for progression-free survival of TNFa -308G > A polymorphism GG and GA genotypes 
in the association analysis. The haplotype frequency data are shown in Table 3. The haplotype analysis confirmed the ACC haplotype connection with younger age (30-40 years) of disease onset $(\mathrm{P}=0.017)$. Non-carriers of ACC haplotype 2.951 times more frequently belonged to older patient subgroup (41 - 50 years) than carriers (95\% CI 1.198 7.273; $\mathrm{P}=0.017)$. GCC and ATA haplotypes did not show any significant associations with the known breast cancer prognostic factors.

\section{Survival Analysis}

In the median follow-up time of 70 months (range 28157), progression was observed for 24 patients. 76 cases were censored. Of those who progressed, 20 had distant metastases. 14 patients with progressive disease died, all due to cancer related death. The data of Cox's proportional hazards regression analysis is shown in Table 4. Kaplan-Meier and Cox's regression analysis did not reveal any significant relationships between the analyzed IL10 -1082A > G, -819 T > C, $-592 \mathrm{~A}>\mathrm{C}$ SNPs and phased haplotypes and PFS, MFS and OS in our study. Cox's regression analysis of TNF $\alpha-308 \mathrm{G}>\mathrm{A}$ SPN has shown a significant disadvantage of GA genotype $v s$. two others in PFS $(\mathrm{P}=0.020$, hazard ratio $(\mathrm{HR})=3.049,95 \%$
$\mathrm{CI}=1.195-7.778)$ and MFS $(\mathrm{P}=0.045, \mathrm{HR}=2.819,95 \%$ $\mathrm{CI}=1.021-7.780)$. During a further analysis of this SNP, we evaluated only the major GG genotype $v s$. heterozygous GA because of a small number of AA genotypes in our population. GG genotype of the TNF $\alpha-308 \mathrm{G}>\mathrm{A}$ polymorphism was significantly associated with a longer PFS by carrying out the Kaplan-Meier analysis, which is graphically shown in Fig. $2(\mathrm{P}=0.014)$. Mean PFS was 119 months in GG genotype group (95 \% CI 108-129) vs. 86 months in GA genotype group (95\% CI 56-116).

As far as MFS is concerned, the benefit of GG genotype vs. GA was also demonstrated by Kaplan-Meier curves ( $\mathrm{P}=0.037$, Fig. 3). The mean time of MFS was 122 months in GG genotype group (95\% CI 112-132) vs. 93,7 months in GA genotype group (95\% CI 64-124). The period of follow-up is rather short to evaluate OS differences, however, preliminary data also shows unequal survival between GG and GA genotypes of TNF $-308 \mathrm{G}>\mathrm{A}$ SNP ( $P=0.036)$ (Fig. 4).

After adjusting to age group, tumor size, histological grade, lymph node status, ER, PR, HER2 status and intrinsic subtype, TNF $\alpha$ GA genotype of TNF $\alpha-308 \mathrm{G}>\mathrm{A}$ SNP remained a significant negative prognostic factor for $\mathrm{PFS}(\mathrm{P}=0.005, \mathrm{HR}=4.631,95 \% \mathrm{CI}=1.587-13.512)$,

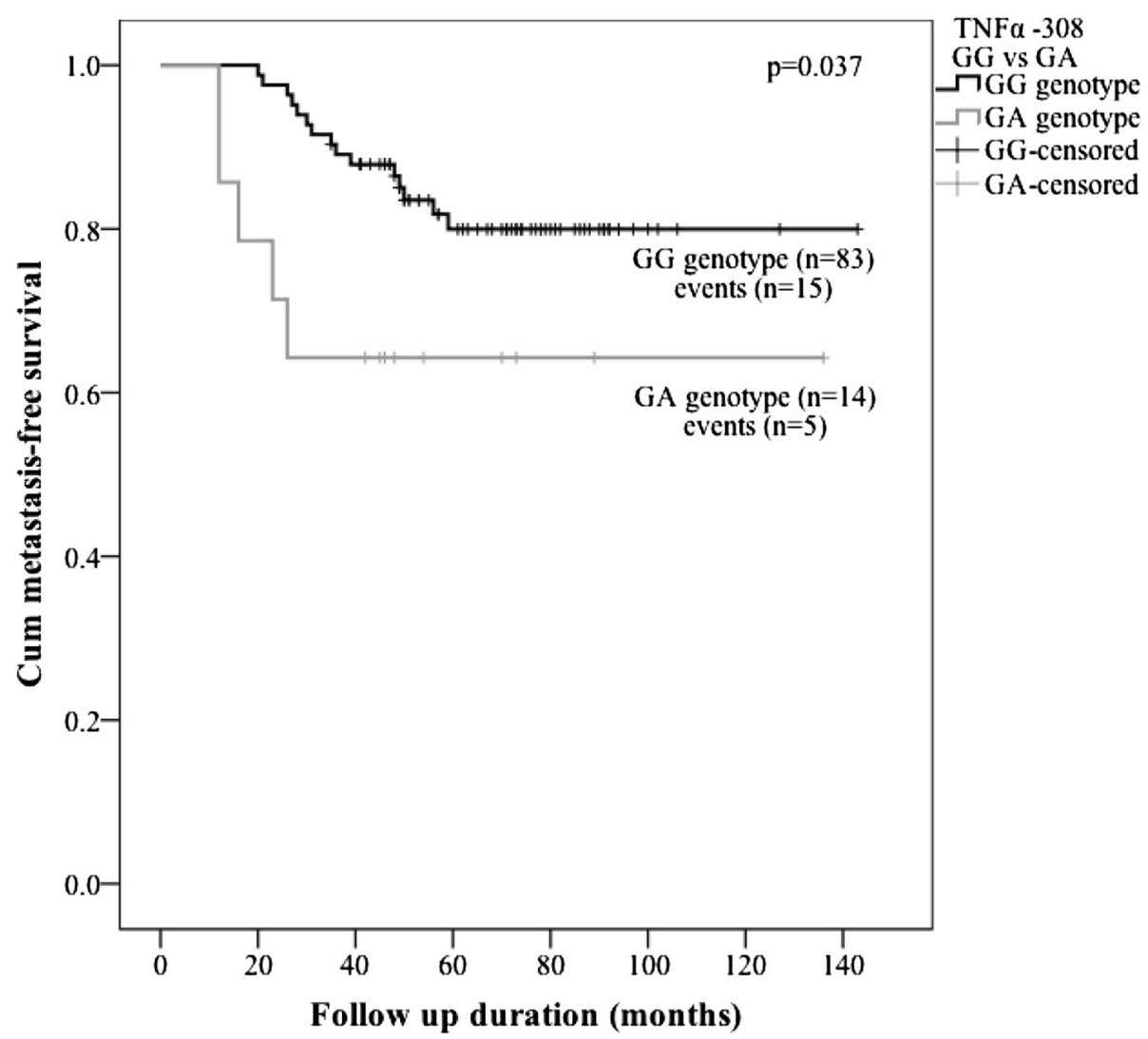

Fig. 3 Kaplan-Meier curves for metastasis-free survival of TNFa-308G > A polymorphism GG and GA genotypes 


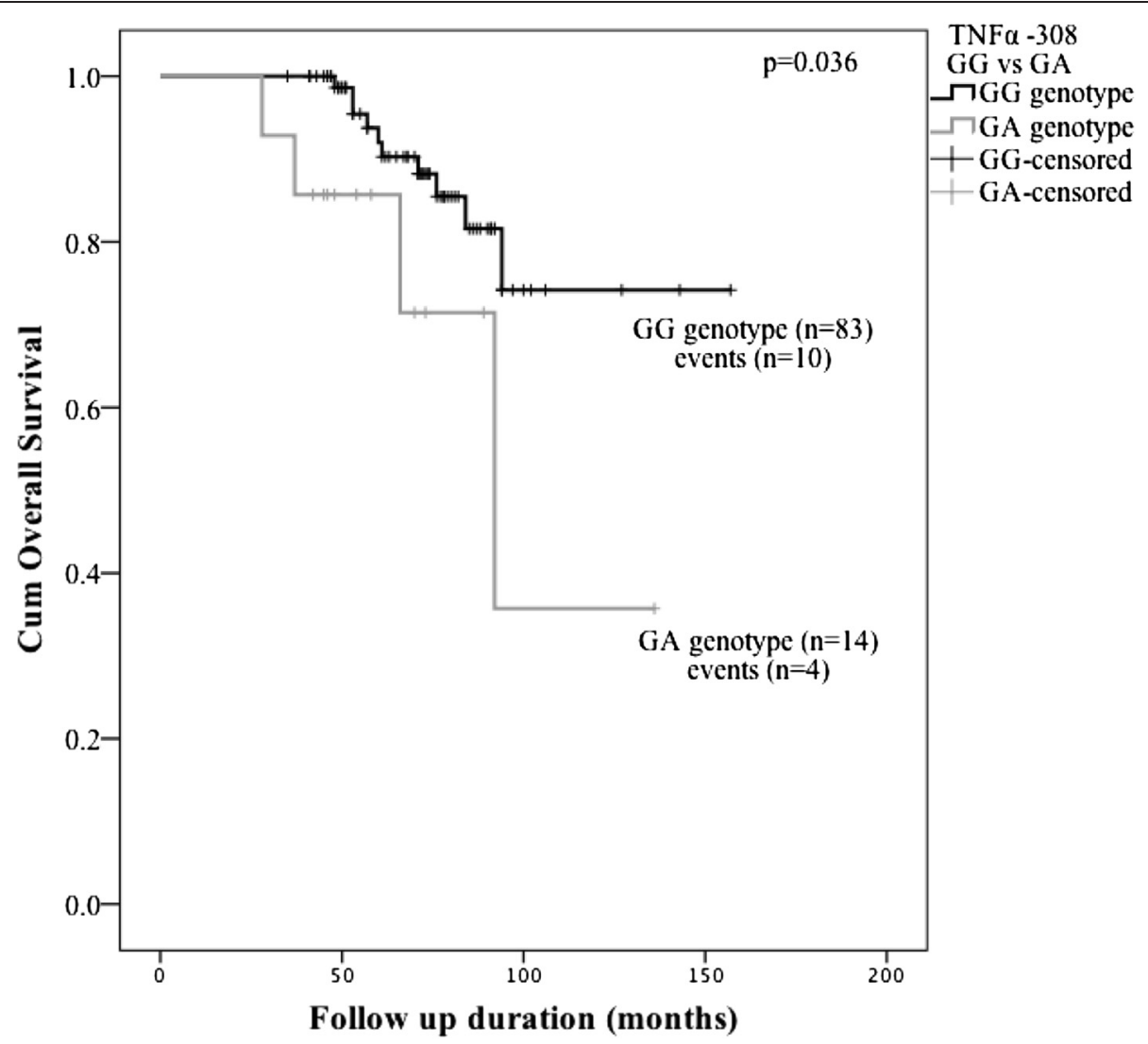

Fig. 4 Kaplan-Meier curves for overall survival of TNFa-308G > A polymorphism GG and GA genotypes

MFS $(\mathrm{P}=0.010, \mathrm{HR}=4.708,95 \% \mathrm{CI}=1.445-15.345)$ and $\mathrm{OS}(\mathrm{P}=0.037, \mathrm{HR}=4.829,95 \% \mathrm{CI}=1.098-21.243)$, which is shown in Table 5.

\section{Discussion}

In this prospective cohort study of 100 premenopausal female patients with early-stage breast cancer, we investigated associations between functional SNPs in IL10 and TNF $\alpha$ genes, previously implicated in breast cancer occurrence, spread and survival. We found that the SNP genotype frequency data of IL10 -1082A > G, -819 T $>$ C, $-592 \mathrm{~A}>\mathrm{C}$ and TNF $\alpha-308 \mathrm{G}>\mathrm{A}$ correspond to HAPMAP project CEU population data and obey the HardyWeinberg law of genetic equilibrium.

IL10 - 1082A > G polymorphism did not show any significant correlation with tumor characteristics, lymph node status and the course of the disease. In the Asian population, Kong et al. showed a larger tumor size for those with AA genotype at position -1082 in comparison to other genotypes and a significantly lower lymph node involvement in patients harboring at least one $\mathrm{G}$ allele of this SNP [15]. However, supporting our results, none of the reported European studies showed this SNP to be associated with tumor phenotype or survival [8, 23-26]. Despite the fact that in earlier studies the $-1082 \mathrm{G}$ allele (which had also been related to higher IL10 expression [10]) was associated with a lower breast cancer risk [27], it seems not to have a major impact on a further course of the disease in our study.

Carriers of IL10 -592A > C heterozygote AC genotype and IL10 -819 T > C CT genotype had a higher probability of ER positive $\mathrm{BC}$ type than homozygote variants. Our data conflict with other authors who did not find any associations of these SNPs with ER status [15, 23, 28]. Furthermore, in the Chinese population, Jingyan et al. [29] did not reveal any significant locus-locus interaction between ER coding genes and IL10 -1082, IL10 -819, or IL10 -592 SNPs, which could explain associations of these SNPs with ER status. However, there is lack of data on this topic in the European population in literature.

Our results of the $I L 10-819 \mathrm{~T}>\mathrm{C}$ and $-592 \mathrm{~A}>\mathrm{C}$ SNP association analysis with other known $\mathrm{BC}$ prognostic factors and survival confirm a few other authors' findings, i. e. those SNPs are neither related with clinicopathological tumor data (except ER status as mentioned earlier) nor with PFS, MFS or OS [15, 23, 25, 30]. However, our data contradict the study of Slattery et al. [31], who have recently showed the IL10 -819 TT genotype as a potential factor for lower cancer risk with OR of 0.79 and Gerger et al. [8], who revealed A-allele of the IL10 -592C > A 
Table 5 Cox's multivariable model. Adjusted hazard ratios for PFS, MFS, OS with each of the known BC prognostic factor and TNFa $-308 \mathrm{G}>\mathrm{A}$

\begin{tabular}{|c|c|c|c|c|c|c|c|}
\hline \multirow[t]{2}{*}{ Variable } & & \multicolumn{2}{|l|}{ Progression-free survival } & \multicolumn{2}{|l|}{ Metastasis-free survival } & \multicolumn{2}{|l|}{ Overall survival } \\
\hline & & Hazard ratio $(95 \% \mathrm{Cl})$ & $P$ value & Hazard ratio $(95 \% \mathrm{Cl})$ & $P$ value & Hazard ratio $(95 \%$ Cl) & $P$ value \\
\hline \multirow[t]{3}{*}{$T N F a-308 G>A$} & GG genotype & 1 & & 1 & & 1 & \\
\hline & GA genotype & $4.631^{*}$ & 0.005 & $4.708^{*}$ & 0.010 & $4.829^{*}$ & 0.037 \\
\hline & & $(1.587-13.512)$ & & $(1.445-15.345)$ & & $(1.098-21.243)$ & \\
\hline \multirow[t]{3}{*}{ Age group } & 41-50 years & 1 & & 1 & & 1 & \\
\hline & $30-40$ years & 1.451 & 0.403 & 1.407 & 0.481 & 1.014 & 0.983 \\
\hline & & $(0.606-3.477)$ & & $(0.544-3.639)$ & & $(0.283-3.634)$ & \\
\hline \multirow[t]{3}{*}{ Tumor size (pathologic) } & $\mathrm{T} 1$ & 1 & & 1 & & 1 & \\
\hline & $\mathrm{T} 2$ & 1.039 & 0.934 & 0.749 & 0.555 & 0.577 & 0.425 \\
\hline & & $(0.419-2.581)$ & & $(0.286-1.960)$ & & $(0.149-2.233)$ & \\
\hline \multirow{3}{*}{$\begin{array}{l}\text { Lymph node involvement } \\
\text { (pathologic) }\end{array}$} & No & 1 & & 1 & & 1 & \\
\hline & N1 & 1.876 & 0.192 & 2.349 & 0.199 & 1.346 & 0.628 \\
\hline & & $(0.729-4.828)$ & & $(0.829-6.659)$ & & $(0.405-4.480)$ & \\
\hline \multirow[t]{5}{*}{ Grade } & G1 & 1 & 0.962 & 1 & 0.751 & 1 & 0.629 \\
\hline & G2 & 1.268 & 0.825 & 1.080 & 0.944 & 0.542 & 0.598 \\
\hline & & $(0.154-10.449)$ & & $(0.127-9.184)$ & & $(0.056-5.268)$ & \\
\hline & G3 & 1.378 & 0.783 & 0.972 & 0.981 & 0.293 & 0.375 \\
\hline & & $(0.141-13.477)$ & & $(0.095-9.965)$ & & $(0.019-4.412)$ & \\
\hline \multirow[t]{7}{*}{ Intrinsic subtype } & Luminal B & 1 & 0.191 & 1 & 0.140 & 1 & 0.119 \\
\hline & Luminal A & 4.095 & 0.178 & 3.329 & 0.225 & 1.380 & 0.780 \\
\hline & & $(0.526-31.892)$ & & $(0.419-26.433)$ & & $(0.144-13.257)$ & \\
\hline & 'Basal-like' & 3.872 & 0.233 & 3.248 & 0.317 & 3.966 & 0.285 \\
\hline & & $(0.420-35.739)$ & & $(0.324-32.593)$ & & $(0.318-49.534)$ & \\
\hline & $\begin{array}{l}\text { HER2 } \\
\text { overexpression }\end{array}$ & $9.874^{*}$ & 0.044 & $10.177^{*}$ & 0.043 & 6.426 & 0.112 \\
\hline & & $(1.068-91.312)$ & & $(1.080-95.880)$ & & $(0.646-63.903)$ & \\
\hline
\end{tabular}

*Significant associations.

polymorphism to have a prognostic value of the reduced DFS with 1.45 risk ratio; yet, controversially, this allele was earlier proved to be linked with a lower BC risk [28].

Due to strong linkage disequilibrium between IL10 $-819 \mathrm{~T}>\mathrm{C}$ and $-592 \mathrm{C}>\mathrm{A}$ SNPs, the presence of ATA haplotype could be determined by analyzing the $-592 \mathrm{C}>\mathrm{A}$ polymorphism: the $-592 \mathrm{~A}$ allele indicated the presence of the ATA haplotype, whereas the $-592 \mathrm{C}$ allele indicated its absence. Phasing revealed three main, well-known haplotypes, namely GCC (41 \%), ACC (32.8 \%) and ATA (26.2 \%). An association between ACC haplotype and younger age of disease onset was found. In the Asian population, as earlier reported [15], the authors discovered ATA haplotype to be associated with a significantly increased risk of lymph node metastasis and a higher tumor size at the time of diagnosis. We did not reproduce these results in the Lithuanian population. ATA haplotype in our study did not show any distinction from other haplotypes in the association and survival analysis. The literature on survival differences among breast cancer patients with different IL10 haplotypes is extremely poor. Data from one small Iranian study support our results [32].

Functional IL10 polymorphisms are of particular interest when describing BC because IL-10 has both potentially cancer-promoting immunosuppressive and potentially cancer-inhibiting antiangiogenic properties. Despite the fact that Langsenlehner et al. [28] revealed that genetically programmed low IL10 expression may be protective in susceptibility to breast cancer, according to our data it seems to have no importance to a further development of the disease.

TNF $\alpha$-308G > A SNP has showed the greatest prognostic potential for BC of all the analyzed SNPs. GA genotype (earlier reported as a high plasma TNF producer) in $\mathrm{BC}$ patients was found to be significantly associated with a poor disease outcome, while wild GG genotype, usually 
linked to low plasma TNF levels, was associated with a better prognosis. The multivariate regression model indicated TNFa -308G > A SNP as an independent prognostic factor for PFS, MFS and OS. As a biological background for these results may serve the fact, that TNF $\alpha$ protein induces an epithelial-mesenchymal transition, namely the process through which cancer cells at the invasive front of primary tumors undergo a phenotypic conversion to invade and metastasize through the circulation and generate a metastatic lesion at distant tissues or organs [33]. A chronic and consistent presence of TNF $\alpha$ in tumors leads to procancerous consequences in many malignant diseases [34]. TNF $\alpha$ is overexpressed in approximately $90 \%$ of patients with recurrent disease [12]. Similarly, Mestiri et al. discovered that the low producer TNF $\alpha-308 \mathrm{G}>\mathrm{A}$ AA genotype was often associated with the reduced DFS and/ or overall survival in patients with breast cancer [35]. Azmy et al. revealed that the carriage of low producer -308A allele might predispose to a more aggressive disease [36]. A study in Tunisia concluded that individuals with the AA genotype were more susceptible to and had worse prognoses in $\mathrm{BC}$ [32]. An Italian study did not demonstrate any association between TNF $-308 \mathrm{G}>\mathrm{A}$ polymorphism genotypes and $\mathrm{BC}$ [27]. Murray et al. [25] failed to confirm TNF alpha polymorphisms as a potential indicator for time to recurrence in Caucasians, African Americans and Hispanics. Controversially, a meta-analysis of Caucasian and Asian ethnicities reported by Fang et al. [14] suggested that the $\mathrm{G}$ allele of $T N F \alpha-308 \mathrm{G}>\mathrm{A}$ is a risk factor for breast cancer development, especially for Caucasians. A contrasting nature of the results of all these studies may be accounted for by sampling error or by differences in ethnicity of patient groups.

We take into consideration a limited sample size, the risk of other confounders and nonrandom sampling. However, this study supports the relevance of TNF $\alpha$ germline polymorphisms to $\mathrm{BC}$ prognosis and our findings hold promise for further investigations, preferable on larger cohorts from different ethnic origins.

\section{Conclusions}

In conclusion, our findings suggest that IL10 -1082A > G, $-819 \mathrm{~T}>\mathrm{C},-592 \mathrm{~A}>\mathrm{C}$ SNPs have no sufficient data of association with the prognosis of BC. Contrary, the $T N F \alpha-308$ polymorphism might modulate the risk and could contribute to the identification of patients at a higher risk of $\mathrm{BC}$ recurrence, metastasis and overall survival in Lithuanian early-stage breast cancer patients. To confirm the validity and utility of these polymorphisms as clinical prognostic biomarkers, future studies of a wider European population are needed.

\section{Abbreviations}

BC: Breast cancer; IL10: Interleukin 10 gene; IL-10: Interleukin 10 protein; TNFa: Tumor necrosis factor alpha gene; TNFa: Tumor necrosis factor protein;
SNP: Single nucleotide polymorphism; A: Adenine; G: Guanine; T: Thymine; C: Cytosine; PCR: Polymerase chain reaction; CEU: Northern Europeans from Utah; DFS: Disease-free survival; MFS: Metastasis-free survival; OS: Overall survival; Cl: Confidence interval; ER: Estrogen receptor; PR: Progesterone receptor; LD: Linkage disequilibrium.

\section{Competing interests}

The authors declare that they have no competing interests.

\section{Authors' contribution}

EK conceived the study, participated in its design, collected clinical data, analyzed the data, performed statistical analyses and drafted the manuscript. DM conceived the study, carried out molecular genetics testing, analyzed the data. RU and DR conceived the study, participated in its design and coordination, data interpretation, carried out molecular genetics testing, collected clinical data and helped to draft the manuscript. JG and EJ conceived the study, participated in its design and coordination, collected clinical data and helped to draft the manuscript. KS participated in data interpretation and performed statistical analyses. All authors read and approved the final manuscript.

\section{Acknowledgements}

We are grateful to the patients for their participation in this research.

\section{Author details}

1Oncology Institute, Lithuanian University of Health Sciences, Eiveniu str. 2, LT-50009 Kaunas, Lithuania. ${ }^{2}$ Oncology Research Laboratory, Oncology Institute, Lithuanian University of Health Sciences, Eiveniu str. 2, LT-50009 Kaunas, Lithuania. ${ }^{3}$ Health Research Institute, Lithuanian University of Health Sciences, Betonuotoju str. 4-9, LT-52371 Kaunas, Lithuania.

Received: 21 April 2015 Accepted: 16 June 2015

Published online: 26 June 2015

\section{References}

1. Dawood S, Broglio K, Ensor J, Hortobagyi GN, Giordano SH. Survival differences among women with de novo stage IV and relapsed breast cancer. Ann Oncol. 2010;21(11):2169-74.

2. Konwar R, Chaudhary P, Kumar S, Mishra D, Chattopadhyay N, Bid HK. Breast cancer risk associated with polymorphisms of IL-1RN and IL-4 gene in Indian women. Oncol Res. 2009;17(8):367-72.

3. Ramkumar HL, de Shen F, Tuo J, Braziel RM, Coupland SE, Shith JR, Chan CC. IL-10 -1082 SNP and IL-10 in primary CNS and vitreoretinal lymphomas. Graefes Arch Clin Exp Ophthalmol. 2012;250(10):1541-8.

4. Chenjiao $Y$, Zili F, Haibin C, Ying L, Sheng $X$, Lihua H, Wei D. IL-10 promoter polymorphisms affect IL-10 production and associate with susceptibility to acute myeloid leukemia. Pharmazie. 2013;68(3):201-6.

5. Howell MW, Rose-zerilli MJ. Cytokine gene polymorphisms, cancer susceptibility, and prognosis. J Nutr. 2007;137 Suppl 1:194-199

6. Eskdale J, Gallagher G, Verweij CL, Keijsers V, Westendorp RGJ, Huizinga TWJ. IL-10 secretion in relation to human IL-10 locus haplotypes. Proc Natl Acad Sci USA. 1998:95:9465-70.

7. Kozlowski L, Zakrzevska I, Tokajuk P, Wojtukiewicz MZ. Concentration of interleukin-6 (IL-6), interleukin-8 (IL-8) and interleukin-10 (IL-10) in blood serum of breast cancer patients. Rocz Akad Med Bialymst. 2003;48:82-4.

8. Gerger A, Renner W, Langsenlehner T, Hofmann G, Knechtel G, Szkandera J, Samonigg H, Krippl P, Langsenlehner U. Association of interleukin-10 gene variation with breast cancer prognosis. Breast Cancer Res Treat. 2010;119(3):701-5

9. Wilson AG, Di Giovine FS, Blakemore AIF, Duff GW. Single base polymorphism in the human tumour necrosis factor alpha (TNF alpha) gene detectable by Ncol restriction of PCR product. Hum Mol Genet. 1992;1:353.

10. Wilson AG, Symons JA, McDowell TL, McDevitt HO, Duff GW. Effects of a polymorphism in the human tumor necrosis factor alpha promoter on transcriptional activation. Proc Natl Acad Sci U S A. 1997:94(7):3195-9.

11. Papadopoulou E, Tripsianis G, Anagnostopoulos K, Tentes I, Kakolyris S, Galazios G, Sivridis E, Simopoulos K, Kortsaris A. Significance of serum tumor necrosis factor-alpha and its combination with HER-2 codon 655 polymorphism in the diagnosis and prognosis of breast cancer. Int J Biol Markers. 2010;25(3):126-35. 
12. Soria G, Ofri-Shahak M, Haas I, Yaal-Hahoshen N, Leider-Trejo L, Leibovich-Rivkin $T$, et al. Inflammatory mediators in breast cancer: coordinated expression of TNFa \& IL-1 $\beta$ with CCL2 \& CCL5 and effects on epithelial-to-mesenchymal transition. BMC Cancer. 2011;11:130.

13. Kirkpatrick A, Bidwell J, van den Brule AJ, Meijer CJ, Pawade J, Glew S. TNFalpha polymorphism frequencies in HPV-associated cervical dysplasia. Gynecol Oncol. 2004;92(2):675-9.

14. Fang F, Yao L, Yu XJ, Yu L, Wu Q, Yu L. TNFalpha -308 G/A polymorphism is associated with breast cancer risk: a meta-analysis involving 10,184 cases and 12,911 controls. Breast Cancer Res Treat. 2010;122(1):267-71.

15. Kong F, Liu J, Liu Y, Song B, Wang H, Liu W. Association of interleukin-10 gene polymorphisms with breast cancer in Chinese population. J Exp Clin Cancer Res. 2010:29:72.

16. Liu J, Song B, Wang JL, Li ZJ, Li WH, Wang ZH. Polymorphisms of interleukin-10 promoter are not associated with prognosis of advanced gastric cancer. World J Gastroenterol. 2011;17(10):1362-7.

17. Kaur A, Kaur A. Recurrent pregnancy loss: TNF-a and IL-10 polymorphisms. J Hum Reprod Sci. 2011;4(2):91-4

18. Hayes DF, Ethier S, Mippman ME. New guidelines for reporting of tumor marker studies in breast cancer research and treatment: REMARK. Breast Cancer Res Treat. 2006;100:237-8.

19. McShane LM, Altman DG, Sauerbrei W, Taube SE, Gion M, Clark GM. Reporting recommendations for tumor MARKer prognostic studies (REMARK). Breast Cancer Res Treat. 2006;100(2):229-235

20. Stephens M, Smith NJ, Donnelly P. A new statistical method for haplotype reconstruction from population data. Am J Hum Genet. 2001;68:978-89.

21. Stephens M, Donnelly P. A comparison of Bayesian methods for haplotype reconstruction from population genotype data. Am J Hum Genet. 2003:73:1162-9.

22. Barrett JC, Fry B, Maller J, Daly MJ. Haploview: analysis and visualization of LD and haplotype maps. Bioinformatics. 2005;21(2):263-5.

23. Smith KC, Bateman AC, Fussell HM, Howell WM. Cytokine gene polymorphisms and breast cancer susceptibility and prognosis. Eur J Immunogenet. 2004;31(4):167-73.

24. Skerrett DL, Moore EM, Bernstein DS, Vahdat L. Cytokine genotype polymorphisms in breast carcinoma: associations of TGF-beta1 with relapse. Cancer Invest. 2005;23:208-14.

25. Balasubramanian SP, Amzy IA, Higham SE, Wilson AG, Cross SS, Cox A, Brown NJ, Reed MW.. Interleukin gene polymorphisms and breast cancer: a case control study and systematic literature review. BMC Cancer. 2006;6:188.

26. Murray JL, Thompson P, Suk Young Y, Kim-anh D, Mala P, et al. Prognostic Value of Single Nucleotide Polymorphisms of Candidate Genes Associated with Inflammation in Early Stage Breast Cancer. Breast Cancer Res Treat. 2013;138(3):917-24.

27. Giordani L, Bruzzi P, Lasalandra C, Quaranta M, Schittulli F, Della Ragione F, Iolascon A. Association of breast cancer and polymorphisms of interleukin-10 and tumor necrosis factor-alpha genes. Clin Chem. 2003;49:1664-7.

28. Langsenlehner U, Krippl P, Renner W, Yazdani-Biuki B, Eder T, Koppel H, Wascher TC, Paulweber B, Samonigg H. Interleukin-10 promoter polymorphism is associated with decreased breast cancer risk. Breast Cancer Res Treat. 2005;90:113-5.

29. Xie J, Wang S, He B, Pan Y, Li Y, Zeng Q, Jiang H, Chen J. Association of estrogen receptor alpha and interleukin 10 gene polymorphisms with endometriosis in a Chinese population. Fertil Steril. 2009;92(1):54-60.

30. Kidd LR, Brock GN, VanCleave TT, Benford ML, Lavender NA, Kruer TL, Wittliff $J$ L. Angiogenesis-associated sequence variants relative to breast cancer recurrence and survival. Cancer Causes Control. 2010;21(10):1545-57.

31. Slattery ML, Herrick JS, Torres-Mejia G, John EM, Giuliano AR, Hines LM, Stern MC, Baumgartner KB, Presson AP, Wolf RK. Genetic variants in interleukin genes are associated with breast cancer risk and survival in a genetically admixed population: the Breast Cancer Health Disparities Study. Carcinogenesis. 2014;35(8):1750-9.

32. Abdolrahim-Zadeh H, Hakkakian N, Asadollahi R, Gharesifard B, Sarvari J, Kamali-Sarvestani E, Talei A. Interleukin-10 Promoter Polymorphisms and Breast Cancer Risk in Iranian Women. Iranian J Immunol. 2005;3:158-65.

33. Zhou C, Nitschke AM, Xiong W, et al. Proteomic analysis of tumor necrosis factor-a resistant human breast cancer cells reveals a MEK5/Erk5-mediated epithelial-mesenchymal transition phenotype. Breast Cancer Res. 2008;10(6):R105.

34. Bertazza L, Mocellin S. The dual role of tumor necrosis factor (TNF) in cancer biology. Curr Med Chem. 2010;17(29):3337-52.
35. Mestri S, Bouaouina N, Ahmed SB, Khedhaier A, Jrad BB, Remadi S. ChouchaneL. Genetic variation in the tumor necrosis factor-alpha promoter region and in the stress protein hsp70-2: susceptibility and prognostic implications in breast carcinoma. Cancer. 2001;91(4):672-8.

36. Amzy IA, Balasubramanian SP, Wilson AG, Stephenson TJ, Cox A, Brown NJ, Reed MW. Role of tumour necrosis factor gene polymorphisms (-308 and -238$)$ in breast cancer susceptibility and severity. Breast Cancer Res. 2004;6(4):R395-400.

\section{Submit your next manuscript to BioMed Central and take full advantage of:}

- Convenient online submission

- Thorough peer review

- No space constraints or color figure charges

- Immediate publication on acceptance

- Inclusion in PubMed, CAS, Scopus and Google Scholar

- Research which is freely available for redistribution 